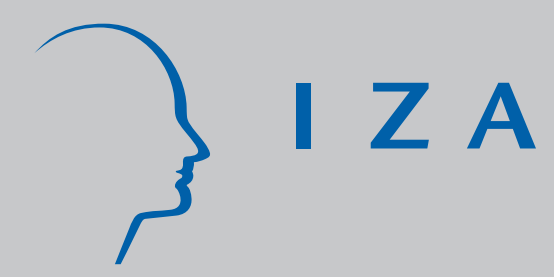

IZA DP No. 1133

Preferences for Rigid versus

Individualized Wage Setting in

Search Economies with Frictions

Tito Boeri

Michael C. Burda

May 2004 


\title{
Preferences for Rigid versus \\ Individualized Wage Setting in Search Economies with Frictions
}

\author{
Tito Boeri \\ IGIER, Bocconi University, \\ CEPR and IZA Bonn \\ Michael C. Burda \\ Humboldt University Berlin, \\ CEPR and IZA Bonn

\section{Discussion Paper No. 1133 \\ May 2004} \\ IZA \\ P.O. Box 7240 \\ 53072 Bonn \\ Germany \\ Phone: +49-228-3894-0 \\ Fax: +49-228-3894-180 \\ Email: iza@iza.org
}

\begin{abstract}
Any opinions expressed here are those of the author(s) and not those of the institute. Research disseminated by IZA may include views on policy, but the institute itself takes no institutional policy positions.
\end{abstract}

The Institute for the Study of Labor (IZA) in Bonn is a local and virtual international research center and a place of communication between science, politics and business. IZA is an independent nonprofit company supported by Deutsche Post World Net. The center is associated with the University of Bonn and offers a stimulating research environment through its research networks, research support, and visitors and doctoral programs. IZA engages in (i) original and internationally competitive research in all fields of labor economics, (ii) development of policy concepts, and (iii) dissemination of research results and concepts to the interested public.

IZA Discussion Papers often represent preliminary work and are circulated to encourage discussion. Citation of such a paper should account for its provisional character. A revised version may be available on the IZA website (www.iza.org) or directly from the author. 


\section{ABSTRACT \\ Preferences for Rigid versus Individualized Wage Setting in Search Economies with Frictions*}

Firing frictions and renegotiation costs affect worker and firm preferences for rigid wages versus individualized Nash bargaining in a standard model of equilibrium unemployment, in which workers vary by observable skill. Rigid wages permit savings on renegotiation costs and prevent workers from exploiting the firing friction. For standard calibrations, the model can account for political support for wage rigidity by both workers and firms, especially in labor markets for intermediate skills. The firing friction is necessary for this effect, and reinforces the impact of both turbulence and other labor market institutions on preferences for rigid wages.

JEL Classification: J5, J6, D7

Keywords: wage rigidities, job protection, firing taxes, renegotiation costs, equilibrium unemployment

Corresponding author:

Tito Boeri

University of Bocconi

Via Salasco 3-5

Milano, 20136

Italy

Email: tito.boeri@uni-bocconi.it

\footnotetext{
* We have benefited from comments of seminar participants in Barcelona (UPF), Berlin, Bonn, Bristol, Konstanz, Mainz, Milan, Tilburg, Uppsala, and the 2003 Ammersee CEPR/IZA Symposium, the World Bank, and in particular, Jim Albrecht, Pietro Garibaldi, Marco Leonardi, Franck Malherbet, Chris Pissarides and Etienne Wasmer. This work is supported by the EU Commission's SER Project "Dynamic Aspects of the European Unemployment Problem" and the SFB 373 (German Science Foundation). We are grateful to Ronald Bachmann, Michael Kvasnicka, Long Kang and Mauro Maggioni for useful research assistance.
} 


\section{Introduction}

Although it is received wisdom among economists that wage rigidity reduces labor market efficiency and welfare, it is puzzling that a broad majority of industrial democracies - especially those in Europe - continue to retain institutions which set wages without reference to local productivity and labor market conditions. The coverage of such rigid wage agreements extends significantly beyond the presence of organised labor at the workplace: in France, "excess coverage" extends to almost 90 per cent of the workforce. ${ }^{1}$ Support for rigid wages is large even in countries which have successfully reformed their labor markets and brought down unemployment. According to a 2001 Eurobarometer survey, $65 \%$ of EU citizens agree with the statement that "workers need strong unions to protect their interests". Similarly, a recent on-line survey on perceptions of institutions conducted by the McKinsey Company revealed that $60 \%$ of Germans consider labor unions to be important for society - compared with $66 \%$ for Greenpeace and $46 \%$ for ADAC, the German automobile club.

A number of economists in recent years, most notably St.-Paul (2000), have grappled with explaining how majorities can arise which favor the retention of institutional arrangements obstructing employment adjustment, such as employment protection legislation. This paper contributes to the literature by focusing on wage rigidity. It demonstrates, under fairly general conditions, that the presence of frictions in equilibrium models of unemployment can generate worker and firm preferences for rigidities in wage setting. The equilibrium search and matching model made popular by Mortensen and Pissarides (1994, 1999a,b) (henceforth MP) delivers the framework for analysis. We distinguish between jobs with match-surplus shared by employers and workers in a decentralised fashion (flexible-wage regime), and those with wages determined outside the parameters of the individual employment relationship (rigid-wage regime).

For our results to obtain, frictions are necessary. We consider two in the MP framework. The first, which is novel, is that worker-firm matches are subject to unavoidable renegotiation costs when productivity changes. These renegotiation costs occur in the individually bargained wage regime and are seen as an inherent aspect of decentralized labor markets. Flexible wage

\footnotetext{
${ }^{1}$ See Boeri, et al. (2001), and Ebbinghaus and Visser (2000) for more details on excess coverage.
} 
setting in a competitive search market is compared with a rigid-wage labor market, in which pay is determined without reference to individual match productivity or labor market slack. The second distortion in the model is a firing tax imposed on separations. While the impact of firing taxes has been studied extensively, their interaction with other labor market institutions is less well-understood. ${ }^{2}$

We show that workers of different skill levels have different preferences over rigid versus flexible wage setting. Using a calibrated version of the model, we can identify significant regions of the skill distribution for which a fixed wage regime is preferred to one in which wages are determined by individual Nash-bargaining. The intuition for our result is straightforward: under Nash-bargaining, a firing tax influences wages positively, because after a match is established, workers cannot commit not to exploit the worsened fallback of firms. Rigid wages provides a mechanism which eliminates this holdup, and this leads to greater job creation, ceteris paribus. The model predicts that support for the rigid-wage regime is stronger at intermediate rather than low skills levels, contrary to conventional wisdom. This is because rigid wages tend to increase job destruction and reduce job creation for the least skilled. Another finding is that while renegotiation costs can increase the value of rigid wage regime to workers, this effect requires the existence of firing frictions. Firing taxes are also found to interact with firm setup or vacancy costs in that the latter increase support for rigid wages in the presence of firing frictions. These complementarities can explain "clusters of institutional rigidities" observed in OECD countries (St.-Paul 2004). Finally, we find that preferences for the rigid wage regime are stronger, notably at the upper end of the skill distribution, when there is more turbulence in the labor market, even when renegotiation costs are negligible.

In the next section, we introduce renegotiation costs in the benchmark MP model of equilibrium unemployment and contrast its behavior with an alternative in which wages are determined by systematic productivity according to an exogenous, rigid rule. Section 3 considers preferences of workers and firms for the two regimes in the context of a calibrated version of the model. Section 4 evaluates how preferences for rigid wages vary in response to changes in underlying institutions. Section 5 concludes.

\footnotetext{
${ }^{2}$ See Ljungqvist (2002) for a survey of theoretical work on the frequently ambiguous effects of severance regulation. Ljungqvist and Sargent (2002) have studied interactions between firing taxes and unemployment benefits. Similar interactions in a different model setting have been studied by Coe and Snower (1997).
} 


\section{Flexible versus Rigid Wage Determination in Equilibrium Unemployment}

\subsection{General description}

Consider a continuum of labor markets indexed by $s \in(0,1]$ where $s$ is a deterministic and observable component of worker productivity. Workers cannot change their skill level, and supply their labor inelastically; they are either unemployed or employed. Firms either produce with one worker, or search with an open vacancy. They can enter freely and search in any labor market at zero cost, but must pay a periodic search, setup or recruitment cost of $s k$ per unit period. Firms can work with all types of workers but only one at any given point in time, and cannot search while employing a worker. When matched, a firm and a worker generate periodic productivity $s x$, where $x \in(0,1]$ is a match-specific component referred to as a "shock." For production to occur, a worker must be matched with a job. All new matches (i.e. filled jobs) begin at the highest possible value of $x(x=1)$. Immediately thereafter, match productivity changes at Poisson frequency $\lambda$, in which case it is a random draw with a fixed, known cumulative distribution $F(x)$.

In both regimes, an exogenous firing tax $s T$ is levied on termination of job-worker matches, with $T<\frac{1}{r+\lambda}$. It is paid to a third party (i.e. is dissipated) and can be thought of as pure deadweight loss, induced either by natural aspects of the employment relationship, or, more likely, by government regulation. These include legal fees paid to lawyers and other third parties when severance is contested, as well severance-related strikes, sabotage, or court-initiated delays in termination of labor contracts. This firing tax is to be distinguished from severance compensation (a lump-sum transfer from employer to employee upon severance), which in principle can be offset by a compensating wage adjustment (see Lazear 1990, Burda 1992, Garibaldi and Violante 2004).

\subsection{Steady-State Equilibrium State Valuations in a La- bor Market of Skill $s$}

Flexible wage regime We first define steady-state, equilibrium valuations of unemployment and employment in a market for labor of arbitrary skill $s$, 
when wages are perfectly flexible. ${ }^{3}$ Given our assumptions, the valuation by workers of unemployment $(U)$, and employment $(W(x))$, and of an open vacancy $(V)$ versus a job $(J(x))$ is given by the following four functional equations:

$$
\begin{gathered}
r U=b+\theta q(\theta)[W(1)-U] \\
r V=-s k+q(\theta)[J(1)-V] \\
r W(x)=w(x)+\lambda \int_{R}^{1}(W(z)-W(x)-\rho) d F(z)+\lambda F(R)(U-W(x)) \\
r J(x)=s x-w(x)+\lambda \int_{R}^{1}((J(z)-J(x)) d F(z)+\lambda F(R)(V-s T-J(x)) .
\end{gathered}
$$

Equations (1) through (4) set normal returns on capitalized valuations of labor market states to their expected periodic payouts. In equation (1), the flow yield from the valuation of the state of unemployment at interest rate $r$ is equated to income in unemployment or leisure equivalent $b$, plus an expected "capital gain" stemming from finding new employment at $x=1$. The ratio of vacancies to unemployment $\theta \equiv v / u$ is a sufficient statistic for labor market tightness and arises from a constant-returns-to-scale matching function $m=m(u, v)$; the probability of a vacancy matching with an unemployed worker is $q=\frac{m(u, v)}{v}=m(\theta, 1)$, with $q^{\prime}(\theta)<0, q^{\prime \prime}(\theta)>0$, and $\lim _{\theta \longrightarrow 0} q(\theta)=\infty$; the probability of an unemployed worker meeting a vacancy is thus $\frac{m(u, v)}{u}=\frac{\theta m(u, v)}{v}=\theta q(\theta)$. Equation (2) determines the valuation of an unfilled vacancy. Given an assumed common startup productivity level for all worker-job matches $(x=1)$, it follows that all vacancies in a given labor market are identical ex-ante.

The function $W(x)$ in (3) returns the value of employment in a job-worker match with current productivity $x$. Given $x$, the implicit rate of return on the asset $W$ is equal to the current wage, which may also depend on $x$, plus the expected capital gain on the employment relationship. Our model is different from the standard MP model in that it incorporates a cost of renegotiation, $\rho$, which is paid whenever the Poisson match-specific productivity shock occurs in order for the match to continue. Formally, the worker

\footnotetext{
${ }^{3}$ Where it is understood to hold for any arbitrary skill group, the subscript for $s$ is suppressed for notational convenience.
} 
pays this cost, but since wages are bargained, both parties will ultimately share the costs of renegotiation in equilibrium. For simplicity, we assume that the renegotiation cost is unavoidable and represents frictions inherent to the continuation of a flexible wage contract. One interpretation of $\rho$ is an unavoidable investment necessary to maintain the existing employment relationship, given that the shock has occurred. Employers' surveys suggest that renegotiation, bargaining, information and organisational costs associated with wage adjustments to plant-level productivity changes can be substantial and discourage the adoption of productivity-related pay structures, even in non-unionised firms. ${ }^{4}$

The lower bound of the definite integral, $R$, is the endogenous cutoff or threshold value of productivity. If idiosyncratic productivity $x$ falls below $R$, the match is no longer profitable and is destroyed. Because match dissolution allows the worker-firm pair to avoid paying $\rho$, the equilibrium value of $R$ will reflect savings on the renegotiation cost realized when the match is destroyed. A similar arbitrage argument determines the valuation to a firm of a filled job in (4), given the current realization of $x$ and for a worker of skill level $s$.

Rigid wage regime By assumption, renegotiation costs can be avoided only by match dissolution. In contrast, they are not incurred at all in the rigid-wage regime, which we now describe. A rigid (or collective) wage labor market is one where labor compensation is independent of local or idiosyncratic influences; i.e. match productivity or market tightness in the particular skill category. It will, however, depend on skill $s$. We will denote this rigid-wage as $w^{r}$. Wage renegotiation costs can be avoided in the rigid-wage regime, where, by construction, the equilibrium state valuations by workers $U^{r}$ and $W^{r}$ in a labor market of skill $s$ are independent of idiosyncratic productivity $x$ :

$$
\begin{gathered}
r U^{r}=b+\theta^{r} q\left(\theta^{r}\right)\left[W^{r}-U^{r}\right] \\
r V^{r}=-s k+q\left(\theta^{r}\right)\left[J^{r}(1)-V^{r}\right] \\
r W^{r}=w^{r}+\lambda F\left(R^{r}\right)\left(U^{r}-W^{r}\right)
\end{gathered}
$$

\footnotetext{
${ }^{4}$ In a survey conducted in September 2000 among 300 small and medium-sized Italian firms, about one-third of the respondents cited wage negotiation costs as a major drawack of plant-level bargaining. Significantly, the employers most concerned about wage negotiation costs were firms in which unions were not represented at the workplace. See www.frdb.org for more details.
} 


$$
r J^{r}(x)=s x-w^{r}+\lambda \int_{R^{r}}^{1}\left(\left(J^{r}(z)-J^{r}(x)\right) d F(z)+\lambda F\left(R^{r}\right)\left(V^{r}-J^{r}(x)-s T\right)\right.
$$

The interpretation of equations (5) through (8) is similar to those of the previous section. Here $R^{r}$ is the reservation productivity from the employer's perspective, which applies to a match in the rigid-wage regime; the job is destroyed for realizations of $x$ lower than $R^{r}$. As in the flexible wage case, $R^{r}$ will take different values for different skill levels and depend on $w^{r}, \phi, T$ and other parameters. Below, we will specify $w^{r}$ in more detail. At this point, it is natural to impose a participation constraint on employment $W^{r} \geq U^{r}$, where $U^{r}$ denotes the value of unemployment for a worker in the rigid wage segment.

Valuation of vacancies in equilibrium There are no restrictions on the entry of firms in any skill segment. Hence, in both regimes the equilibrium value of vacant jobs will satisfy the free entry condition $V=V^{r}=0$. In the flexible wage regime, (2) becomes

$$
J(1)=\frac{s k}{q(\theta)}
$$

and in the rigid-wage regime

$$
J^{r}(1)=\frac{s k}{q\left(\theta^{r}\right)}
$$

\subsection{Wage Determination}

Flexible wage regime In the individualized wage setting regime, workers' remuneration is determined by a Nash sharing rule. ${ }^{5}$ For an existing match in the competitive labor market, the Nash-bargained wage is given by

$$
w(x)=\arg \max _{w}[W(x)-U]^{\beta}[J(x)+s T-V]^{(1-\beta)}
$$

yielding the first order condition

$$
W(x)-U=\beta[J(x)+W(x)+s T-V-U] .
$$

\footnotetext{
${ }^{5}$ Here we follow MP (1999a,b) and Pissarides (2000); for details see the Appendix. Detailed derivations of these and other results in this paper are available in a longer appendix available from the authors upon request.
} 
It is convenient to solve first for the steady-state valuation of unemployment $U$. Combining (9) and $V=0$ with (11) evaluated at $x=1$ and inserting the result into (1) yields

$$
r U=b+\frac{\beta s k \theta}{1-\beta} .
$$

The equilibrium state valuation of unemployment is linear in $\theta$, which is a sufficient statistic for tightness in labor markets. Following Mortensen and Pissarides (1999a,b) we use (12) to obtain the equilibrium wage rule:

$$
w(x)=(1-\beta)[b+\lambda(1-F(R)) \rho]+\beta s(k \theta+x+r T) .
$$

Notice that the equilibrium wage depends not only on familiar parameters such as $b$ (the monetary value of unemployment or leisure), $\theta$ (labor market tightness), $x$ (match productivity), and $T$ (firing tax), but also on $\lambda$, the shock probability, and the renegotiation cost $\rho$. These latter two factors are more important, the more likely a job is to survive $(1-F(R))$. Idiosyncratic productivity shocks which do not lead to match dissolution make the worker partially liable for renegotiation costs. By abandoning the match and passing into unemployment, renegotiation costs can be avoided; consequently, a higher wage is needed to indemnify for this contingency. Effectively, the fallback of the worker is increased by the savings on future renegotiation costs that is implied by a breakdown of negotiations and spell of unemployment. ${ }^{6}$ The more power the employer has, the more likely the wage will reflect this "compensating differential" as opposed to insider rents. In contrast, bargaining power of workers links wages more tightly with idiosyncratic productivity, local market conditions, as well as the lock-in effect of the firing tax.

Rigid wage regime Rigid wages are assumed to depend positively on observable productivity $s$, so $w^{r}=w^{r}(s)$ with $\frac{d w^{r}}{d s}>0$. We parametrize the wage schedule by

$$
w^{r}=\bar{w}+\phi s
$$

with $0<\phi<1$, where $\bar{w} \geq b$ is a social minimum or minimum wage, while $\phi$ reflects skill-dependence of compensation independent of match productivity. Low values of $\phi$ suggest "egalitarian" wage structures, with higher values linking pay more tightly to systematic (deterministic) productivity.

\footnotetext{
${ }^{6}$ Notice that the hold-up problem (Malcomson, 1997) does not arise in this context because the incidence of $\rho$ is, by assumption, not subject to negotiation.
} 


\subsection{Job Creation, Destruction and Equilibrium}

\subsubsection{Job Creation}

Flexible wage regime The derivation of the job creation condition in the flexible regime follows Pissarides (2000):

$$
\frac{(1-\beta)(1-R)}{r+\lambda}-T=\frac{k}{q(\theta)}
$$

This condition on $R$ and $\theta$ is represented in the left panel of Figure 1 by the downward-sloping $J C$-curve (for job creation). ${ }^{7}$ Note that neither $s$ nor $\rho$ affects the position of the JC curve. Wage renegotiation costs do not affect the incentive to create a job at any given skill level, but rather influence the viability of the job via the surplus available to the match. Insofar as setup costs are proportional to skill in the particular labor market, there is no bias on the job creation margin in favour of a particular skill level.

Rigid wage regime The job creation condition for a job in the rigid wage labor market is shown in the Appendix to be given by

$$
\frac{1-R^{r}}{r+\lambda}-T=\frac{k}{q\left(\theta^{r}\right)}
$$

The JC curve in the rigid labor market is plotted in the right panel of Figure 1. It remains strictly downward sloping in $\left(\theta^{r}, R^{r}\right)$-space, since $q^{\prime}<0$, and lies everywhere above that of the competitive labor market. It is also independent of skill level $s$.

\subsubsection{Job Destruction}

Flexible wage regime As in the MP model, jobs are destroyed when productivity falls below its corresponding reservation or threshold level. In the individual-bargaining regime, $R$ is implicitly defined for each skill $s$ by the condition

$$
J(R)=-s T \text {. }
$$

\footnotetext{
${ }^{7}$ Implicit differentiation of (15) gives $\frac{d R}{d \theta}=\frac{(r+\lambda) k q^{\prime}}{(1-\beta) s q^{2}}$, where $f$ is the density associated with $F$. Since $q^{\prime}(\theta)<0, \frac{d R}{d \theta}<0$ unambiguously.
} 
At the same time, Nash bargaining also implies that $R$ satisfies the zero match-surplus condition:

$$
J(R)+s T-V+W(R)-U=0
$$

and, given the free entry condition $V=0$, it follows that

$$
W(R)=U,
$$

that is, in this regime separations are privately, but not necessarily socially, efficient in the sense of Hosios (1990).

The reservation productivity level for the competitive search market, $R$, is determined implicitly by the job destruction condition ${ }^{8}$ :

$$
s R+\frac{s \lambda}{r+\lambda} \int_{R}^{1}(z-R) d F(z)+r s T=b+\frac{\beta s k \theta}{1-\beta}+\lambda[1-F(R)] \rho
$$

The left-hand side is the flow benefit of a continuing match with productivity $R$; this is the current flow product plus the option value deriving from possible future improvements over the following time interval. The right-hand side represents the (opportunity) costs of maintaining the match at the threshold value of idiosyncratic productivity, plus the expected value of renegotiation costs. This job destruction (JD) condition defines an upward-sloping curve in the $(\theta, R)$ space, which we show in the left panel of Figure $1 .{ }^{9}$

Rigid wage regime The hallmark of the rigid wage regime is that the value of a job to the employee is independent of match productivity. Hence, the set of idiosyncratic productivities for which the job is destroyed will not necessarily coincide with those for which the job has zero value to the worker. Rather, the participation constraint implies that for a given skill level, $W^{r}\left(R^{r}\right)=W^{r}>U^{r}$. In rigid-wage labor markets, the "consensual" dissolution of an employment relationship no longer applies, and there are always too many separations from the workers' perspective. Separations are inefficient in the sense that for some range of productivities workers will be fired, but at the given wage, they would prefer to continue working. Except

\footnotetext{
${ }^{8}$ The derivation of this condition is standard and can be found in Mortensen and Pissarides (1999b) or Pissarides (2000).

${ }^{9}$ Differentiate (19) and solve for $d R / d \theta$ to obtain $\frac{d R}{d \theta}=\frac{\frac{\beta k}{1-\beta}}{s\left[1-\frac{\lambda}{r+\lambda}(1-F)\right]+\lambda f \rho}>0$.
} 
on a set of measure zero, there are only involuntary layoffs in the rigid wage regime. In contrast, quits and layoffs are indistinguishable in the flexible wage regime. ${ }^{10}$

Because the rigid wage is not the outcome of individual level bargaining, surplus division obeys a rule of the residual claimant type. Let $S^{r}(x)$ be the total surplus resulting from a match for any $s$, so for any $x \in\left[R^{r}, 1\right]$

$$
J^{r}(x)=\max \left(-s T, S^{r}(x)-\left(W^{r}-U^{r}\right)\right) .
$$

The firm obtains all surplus greater than $\left(W^{r}-U^{r}\right)$. The maximum operator applies since the firm can always close operation, here at cost $s T$. Unlike the individual-wage labor market, the decision to destroy a job is taken by employers unilaterally and given by $J^{r}<-s T$ for any $s$; yet in general at this point $W^{r}>U^{r}$. The reservation productivity $R^{r}$ for a match for skill level $s$, that is, the reservation value for jobs under rigid wages is given by (see Appendix):

$$
s R^{r}+\frac{\lambda s}{r+\lambda} \int_{R^{r}}^{1}\left(x-R^{r}\right) d F(x)+r s T=\bar{w}+\phi s
$$

Unlike the flexible, individually bargained wage case, the component related to renegotiation costs is absent. This expression represents the job destruction condition in the rigid search market, the JD-curve, which is plotted in $\left(\theta^{r}, R^{r}\right)$ space in Figure 2. The JD curve is horizontal, reflecting the independence of $R^{r}$ of local labor market conditions. The unambiguous effect of increasing the firing tax $T$ is evident from the figure: it reduces the job destruction threshold and raises the average duration of a job.

In contrast to (19), neither labor market tightness $\left(\theta^{r}\right)$ nor individual worker bargaining strength $(\beta)$ appear in the job destruction condition. The rigid wage influences the outcome via $R^{r}$, which is endogenously determined as the intersection of the JC and JD curves for every $s$. As in the flexible wage labor market, an increase in $\lambda$ ceteris paribus shifts back the job destruction curve towards the origin.

\subsubsection{Equilibrium}

Flexible wage regime. The intersection of the job destruction curve (19) with the job creation curve (15) defines a labor market equilibrium for sub-

\footnotetext{
${ }^{10}$ Quits by workers cannot result in material gains, by assumption. Allowing for on-thejob search is a subject for future research.
} 
market with skill $s$. For each skill level there exists a unique equilibrium reservation productivity and labor tightness pair $\left(R^{*}, \theta^{*}\right)$ given by the implicit functions of deterministic productivity $s$, the Poisson arrival rate $\lambda$, worker bargaining power $\beta$, vacancy setup costs $k$, renegotiation costs $\rho$, income-equivalent in unemployment $b$, and firing $\operatorname{tax} T$ :

$$
\begin{aligned}
R^{*} & =R^{*}(s, \lambda, \beta, k, \rho, b, T) \\
\theta^{*} & =\theta^{*}(s, \lambda, \beta, k, \rho, b, T) .
\end{aligned}
$$

The result is depicted as the intersection points in the left panel of Figure 1.

Given the equilibrium $R^{*}$ and $\theta^{*}$, the unemployment rate in a market for skill $s$ can be derived using the familiar stock-flow condition for constant unemployment:

$$
u^{*} \equiv u^{*}(s, \lambda, \beta, k, \rho, b, T)=\frac{\lambda F\left(R^{*}\right)}{\lambda F\left(R^{*}\right)+\theta^{*} q\left(\theta^{*}\right)} .
$$

Rigid wage regime. Similarly, the intersection of the JD and the JC curves depicted in the right panel of Figure 1 gives unique equilibrium values of the reservation productivity and market tightness for the labor market under the rigid wage regime, which we call $R^{r}=R^{r}(s, \lambda, k, \bar{w}, \phi, b, T)$ and $\theta^{r}=\theta^{r}(s, \lambda, k, \bar{w}, \phi, b, T)$ respectively. Analogous to (22), the equilibrium unemployment rate $u^{r}$ in a rigid-wage labor market for skill $s$ is given by

$$
u^{r}=\frac{\lambda F\left(R^{r}\right)}{\lambda F\left(R^{r}\right)+\theta^{r} q\left(\theta^{r}\right)} \equiv u^{r}(s, \lambda, k, \bar{w}, \phi, b, T) .
$$


Figure 1: EQUILIBRIUM IN LABOR MARKETS OF ARBITRARY SKILL $s$ WITH A) FLEXIBLY BARGAINED WAGES AND B) RIGID WAGES

A)

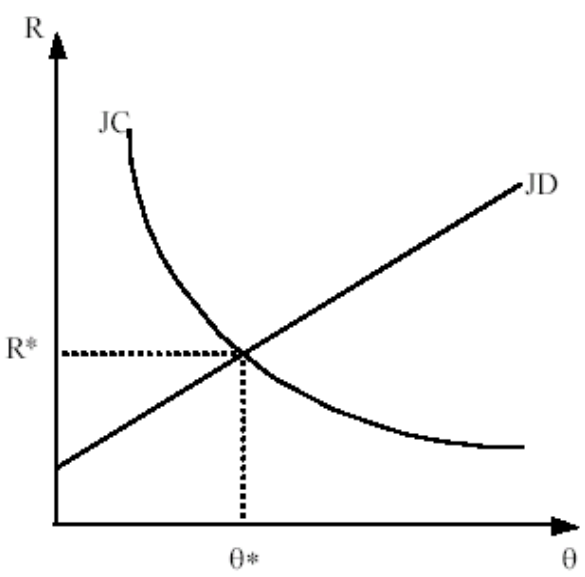

B)

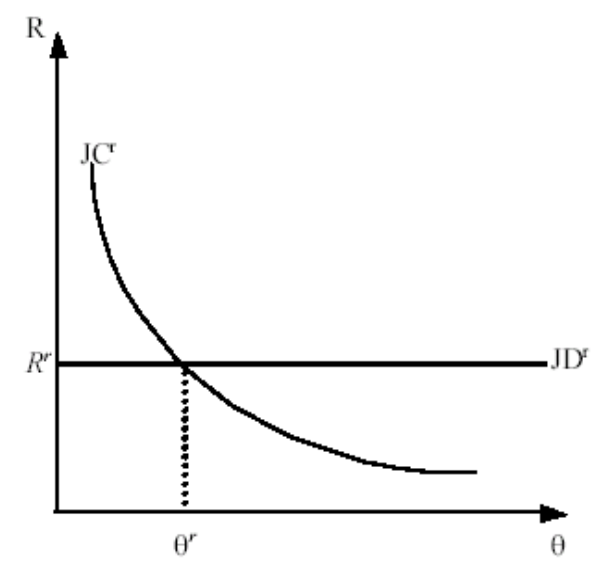

\subsubsection{Comparative Statics}

The dependence of the endogenous variables on the model parameters in the two regimes is described in the table below.

Table 1. Comparative Statics Results

\begin{tabular}{|c|c|c|c|c|c|c|c|c|c|}
\hline Effect of & $\Downarrow$ & $s$ & $\lambda$ & $\rho$ & $b$ & $\beta$ & $T$ & $\bar{w}$ & $\phi$ \\
\hline \multirow{3}{*}{$\begin{array}{l}\text { Flexible wage } \\
\text { regime }\end{array}$} & \multirow{3}{*}{$\begin{array}{c}R^{*} \\
\theta^{*} \\
u^{*}\end{array}$} & $\overline{c-}$ & $\bar{~}+$ & $\bar{~}+$ & $\overline{c+}$ & $\bar{~}+$ & - & & \\
\hline & & + & - & - & - & - & - & & \\
\hline & & - & + & + & + & + & $?$ & & \\
\hline \multirow{3}{*}{$\begin{array}{l}\text { Rigid wage } \\
\text { regime }\end{array}$} & \multirow{3}{*}{$\begin{array}{c}R^{r} \\
\theta^{r} \\
u^{r}\end{array}$} & - & + & & + & & - & + & + \\
\hline & & + & - & & - & & - & - & - \\
\hline & & - & + & & + & & $?$ & + & + \\
\hline
\end{tabular}

An increase in $s$ shifts the JD curve downwards and the JC curve outwards from the origin, so an increase in skill unambiguously tightens the labor market and lowers the firing threshold in both regimes. An increase in the frequency of productivity shocks, renegotiation costs or the value of 
leisure increases unemployment in the flexible labor markets via their effects on wages. To the extent that a rigid wage does not depend on $b, \lambda$ and $\rho$ (and $\bar{w}$, if it is strictly greater than $b$ ), job creation and destruction margins (hence unemployment) are unaffected by changes in these parameters. As noted above, increases in the minimum wage and in the slope of the wageskill profile in the rigid segment have unambiguous effects on job duration (negative), market tightness (negative) and unemployment (positive). Finally, the firing tax reduces both job creation and destruction while its effect on unemployment is ambiguous.

\subsection{Closed Labor Markets}

A market for labor may not exist for every skill level. A labor market is said to be open if $\theta>0$, i.e., if positive vacancies are observed; if no vacancies are posted, the unemployment rate is $100 \%$ and the labor market is closed. ${ }^{11}$ Alternatively, a labor market is closed if there is no value of $x \in(0,1]$ for which match surplus is positive. It is useful to define $\underline{s}$ as the skill level above which labor markets are open. In the case of individualized, flexible wagesetting, as $\theta \rightarrow 0$, the $\mathrm{JC}$ condition (15) implies that $R^{*}$ approaches $1-\frac{(r+\lambda) T}{1-\beta}$ from below. Consequently, labor markets are closed for $R^{*} \in\left[1-\frac{(r+\lambda) T}{1-\beta}, 1\right]$. The JC condition for the rigid wage regime (16) contains the same implication for $R^{*} \in[1-(r+\lambda) T, 1]$. It follows that the maximal skill at which the flexible labor market is closed, $\underline{s}^{*}$, can be found by inverting $q($.$) in (15) for$ $\theta$, substituting the result in the job destruction condition, solving for $s$, and taking the limit as the threshold approaches $1-\frac{(r+\lambda) T}{1-\beta}$ from below:

$$
\begin{aligned}
\underline{s}^{*} & =\frac{b+\lambda\left[1-F\left(1-\frac{(r+\lambda) T}{1-\beta}\right)\right] \rho}{1-\frac{(r+\lambda) T}{1-\beta}+\frac{\lambda}{r+\lambda} \int_{1-\frac{(r+\lambda) T}{1-\beta}}^{1}\left(z-\left[1-\frac{(r+\lambda) T}{1-\beta}\right]\right) d F(z)+r T} \\
& =\frac{r+\lambda}{r\left(1-\beta \frac{(r+\lambda) T}{1-\beta}\right)+\lambda F\left(1-\frac{(r+\lambda) T}{1-\beta}\right)}\left[b+\lambda\left[1-F\left(1-\frac{(r+\lambda) T}{1-\beta}\right)\right] \rho\right] \\
& >b+\lambda\left[1-F\left(1-\frac{(r+\lambda) T}{1-\beta}\right)\right] \rho>b .
\end{aligned}
$$

\footnotetext{
${ }^{11}$ Since there is no gain from keeping a worker with a productivity which does not cover the opportunities costs of both parties, no worker should ever be observed working at a wage lower than $b$.
} 
Note that when $\rho=T=0$, then $b$ is the lower bound for match productivity, below which labor markets are closed; match productivity at the outset must strictly exceed the flow benefit from leisure. The lower bound is greater than $b$, however, when $T>0$, a fact that has been neglected in the literature. In principle, labor markets can be closed even if workers in these skill classes have productivity strictly exceeding $b$.

When wages are rigid, the same analysis as above can be applied to (16) and (21) as $R^{r}$ approaches $1-(r+\lambda) T$, resulting in:

$$
\begin{aligned}
\underline{s}^{r} & =\frac{\bar{w}}{1-\lambda T+\frac{\lambda}{r+\lambda} \int_{1-(r+\lambda) T}^{1}(x-[1-(r+\lambda) T]) d F(x)-\phi} \\
& =\frac{r+\lambda}{r(1-\phi)+\lambda(1-\phi-F(1-(r+\lambda) T)} \bar{w}>\bar{w}
\end{aligned}
$$

By inspection, rigid-wage labor markets may be closed not only due to the direct effect of the minimum wage $\bar{w}$ exceeding maximum match productivity $s$, but also by $\phi$ and $T$, which creates a range of productivity values exceeding $\bar{w}$ for which workers are not employed.

\section{Worker and Firm Preferences for Labor Mar- ket Regimes: A Calibration}

\subsection{Model Specification}

The objective of this section is to evaluate the properties of a calibrated version of the model with particular functional forms. In particular, we are interested in evaluating preferences of workers and firms in markets for different skill classes for the two regimes. We thus follow a tradition initiated by Millard and Mortensen (1997) and Mortensen and Pissarides (1999) in analyzing the effects of labor market institutions. We consider an economy with matching success probabilities given by the power functional form $q(\theta)=$ $A \theta^{-\alpha}$ with $A>0,0<\alpha<1$. The idiosyncratic shock is distributed uniformly over the interval $(0,1]$. Under these conditions, the job creation condition for market of skill $s$ in the flexible search labor market is given by

$$
\theta^{*}=\left[\frac{A}{k}\left(\frac{(1-\beta)(1-R)}{r+\lambda}-T\right)\right]^{1 / \alpha}
$$


while in the rigid search market it is characterized by the condition

$$
\theta^{r}=\left[\frac{A}{k}\left(\frac{1-R^{r}}{r+\lambda}-T\right)\right]^{1 / \alpha} .
$$

The job destruction conditions are respectively

$$
s R^{*}+\frac{s \lambda\left(1-R^{*}\right)^{2}}{2(r+\lambda)}=b+\frac{\beta s k \theta^{*}}{1-\beta}+\lambda\left(1-R^{*}\right) \rho-r s T
$$

and

$$
s R^{r}+\frac{s \lambda\left(1-R^{r}\right)^{2}}{2(r+\lambda)}=\bar{w}+\phi s-r s T .
$$

Equilibria exist when $R \in(0,1]$ and $0<\theta<\infty$. The critical value of skill for which markets are closed in the flexible wage economy is given by

$$
\underline{s}^{*}=\frac{(r+\lambda)\left[b+\frac{\lambda(r+\lambda) T}{1-\beta} \rho\right]}{r\left(1-\frac{\beta(r+\lambda) T}{1-\beta}\right)+\lambda\left(1-\frac{(r+\lambda) T}{1-\beta}\right)}
$$

and in the rigid wage economy by

$$
\underline{s}^{r}=\frac{(r+\lambda) \bar{w}}{r(1-\phi)+\lambda[(r+\lambda) T-\phi]}
$$

\subsection{Numerical values and characteristics of the model economy}

Figure 2 displays the two value functions under the assumptions outlined above for each of the two regimes, calibrated using parameter values given in Table 2. Values chosen for $\lambda$ and $k$ are close to those used by Yashiv (2000) for a calibration of the MP model to Israeli data, as well as by Mortensen and Pissarides (1999a) in their evaluation of labor market policies. The minimum wage $\bar{w}$ is arbitrarily set just at unemployment income, which is itself established at a level leaving about one-sixth of the skill distribution out of employment under competitive conditions. It is difficult to find empirical counterparts of the pay scale parameter $\phi$, as econometric estimates of union wage premia also reflect rent capture in particular industries and do not control for actual coverage (beyond membership) of collective bargaining. Estimates reported by Booth (1995, Chapter 6) imply an egalitarian 
wage-skill profile with higher premia for low and intermediate skill levels. Accordingly, we set $\phi$ at 0.55 , which implies that the top decile of the skill ladder of open labor markets is paid about 3 times more than the bottom decile. We impose the Hosios condition on the matching function (Hosios 1990), so an undistorted decentralized equilibrium would achieve the (restricted) social optimum. The value for the renegotiation costs is admittedly arbitrary. In the baseline simulation it is set equal to $20 \%$ of one quarter's output. Recall that the renegotiation costs represent the monetary valuation of all (including intangible) costs of rewriting the contract for the entire workforce of a firm upon the realization of a idiosyncratic productivity shock. Finally, the value of the firing tax is set at three months of output, which means roughly $4-5$ months of pay.

TABLE 2. PARAMETER VALUES FOR BASELINE CALIBRATION
\begin{tabular}{|l|c|}
\hline$A$ (matching function effectiveness) & 0.60 \\
\hline$\alpha=\beta$ (elasticity of $q(\theta)$ and labor bargaining power) & 0.50 \\
\hline$b$ (income in unemployment) & 0.15 \\
\hline$\lambda$ (frequency of the match-specific shock) & 0.10 \\
\hline$r \quad$ (real interest rate per quarter) & 0.05 \\
\hline$\rho$ (renegotiation or match maintenence costs) & 0.20 \\
\hline$k$ (startup/vacancy costs, proportional to productivity) & 0.15 \\
\hline $\bar{w}$ (base or minimum wage) & 0.15 \\
\hline$\phi$ (pay scale parameter) & 0.55 \\
\hline$T$ (firing tax, proportional to productivity) & 1.00 \\
\hline
\end{tabular}

Assuming a uniform distribution of workers across skill classes, the equilibrium in the decentralized economy with the baseline calibration has a mean unemployment rate of $6.4 \%$ with a mean and median completed steady state unemployment duration of 1.2 and 1.0 quarters, respectively. In the rigid wage economy, the unemployment rate is $6.2 \%$ with a mean (median) duration of $3.3(0.4)$ quarters. The striking deviation of median from mean in the rigid case results from wage rigidity, and is reflected in the wide range of unemployment rates from a low of $1.4 \%$ to a high of $93 \%$. This range of equilibrium unemployment rates is absent from the flexible wage economy, since bargained wages decline when labor markets are soft ( $\theta$ is low). As a result, labor markets are open for $81 \%$ of the productivity classes, compared with only $60 \%$ in the rigid wage economy. ${ }^{12}$

\footnotetext{
${ }^{12}$ Note that the unemployment rate is the average rate of unemployment of those labor markets which are operating, so in the rigid wage regime, the unemployment rate will
} 


\subsection{Results}

The valuations of the state of employment and of a filled job under both regimes are derived in the Appendix. In Figure 2, these valuations are plotted by skill $s$ for the baseline calibration. As can be seen, the labor market is shut down for the lowest skill levels in both segments. Intermediate skill levels tend to place a higher valuation on the rigid regime. Higher-skill workers prefer to have their wages set under competitive conditions, as do the lowest skill classes open under both regimes. Local sensitivity analysis of the calibration around the baseline reveals that the fraction of those working in rigid labor markets which prefer them to competitive markets is positively related to the interest rate, the Poisson incidence parameter $\lambda$, the productivity pay parameter $\phi$, the base wage $\bar{w}$, the cost of renegotiation $\rho$ and the firing tax $T$.

In Figure 2, preferences of employed workers for the regime clearly depend on skill, so the distribution of skill in the economy will play a pivotal role in determining aggregate preferences. In our base calibration depicted above, workers with skill levels $s=[0.45,0.74]$ will prefer the rigid wage regime, while workers with skill in the intervals $[0.21,0.44]$ and $[0.75,1.00]$ prefer the competitive regime. With uniform distribution of skill, if the two alternatives were subjected to a vote among those working in labor markets open under both regimes (with skills in the interval $[0.42,1.00]$ the rigid regime would defeat the flexible economy in a one-on-one election. A median voter in favor of rigid wages would be more likely with significant mass in the middle of the skill distribution. Overall, the extent of preference for the rigid wage regime we find should be considered a lower bound, as we have restricted our attention to a simple, linear rule describing wage determination. In the class of more general functions relating wage to observable skill, it is likely that other rules are superior to (14).

It is also noteworthy that firms working with $50 \%$ of all potential skill levels and about two-thirds of all firms in operation in the rigid wage regime will favor maintaining it. This is because for reasonable values of $\phi$, firms profit more from high productivity workers in the rigid regime. In this model, "capitalists" are likely to favor the rigid wage regime, unless they operate with low productivity labor, in which case they will lobby for regime change.

significantly understate the nonemployment rate, which includes closed markets. 
Figure 2: Equilibrium State Valuations in the two Regimes, BaseLiNE CALIBRATION

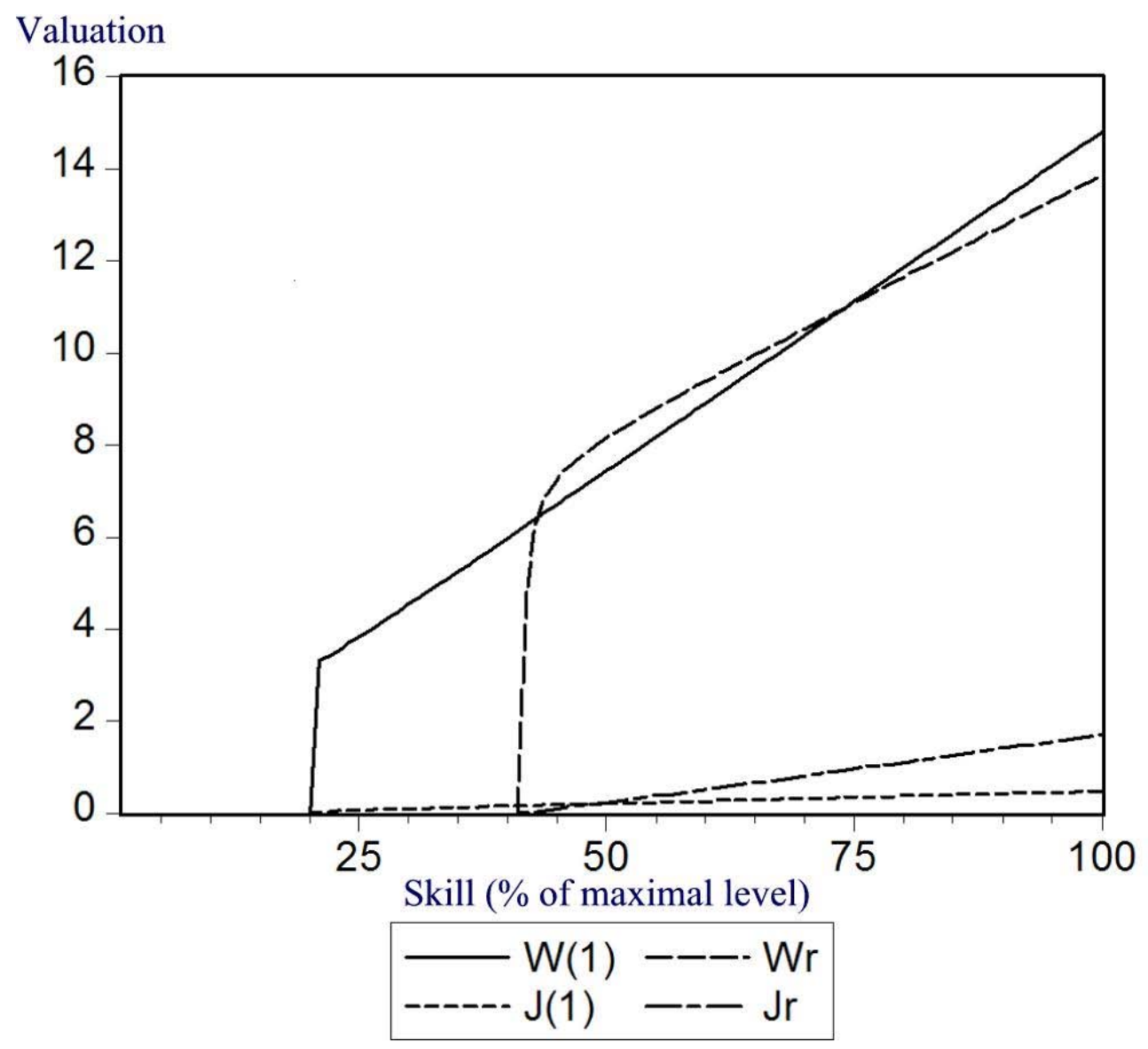




\section{Interactions between Labor Market Insti- tutions and Preferences for Rigid Wages}

\subsection{Renegotiation Costs versus Firing Taxes}

Figure 3 displays valuation of filled jobs $\left(W(1)\right.$ and $\left.W^{r}\right)$ and filled jobs $(J(1)$ and $\left.J^{r}(1)\right)$ for the baseline case, with variation across the renegotiation cost $\rho \in\{0,0.25,0.5\}$ and the firing tax $T \in\{0,0.75,1.25\}$. Taken alone, levels of renegotiation costs $\rho$ necessary to induce significant support for a rigid wage regime are too large to be realistic. The results suggest that - at least for models obeying the Hosios condition in the absence of significant frictions the Nash sharing rule delivers outcomes in the MP model that are unlikely to be improved upon. This is evident from the upper left-hand panel of the Figure 3.

Figure 3 does show clearly, however, that the relative attractiveness of the rigid wage regime is enhanced as the firing tax increases $(T>0)$. The greater the firing friction, the more popular rigid wages are likely to be. This prediction is consistent with the observation of union support for labor market regulation as well as the correlation of employment protection legislation with union organization (e.g., Boeri, Brugiavini and Calmfors, 2001; Checchi and Lucifora, 2002). Statutory severance pay and, more broadly, employment protection legislation appear to be a complement to wage rigidities, rather than a substitute, as in the models predicting that support for unions should decline when employment protection is a public good (Booth 1995). Our result is related to Bruegemann's (2004) finding that when wages are rigid, workers are more likely to support job protection because they face involuntary separations. Our intuition is related to the fact that the firing $\operatorname{tax} s T$ enters the wage equation (13) with a positive sign (multiplied by the interest rate and the bargaining power parameter). This means that regimes with higher firing taxes will have higher wages under Nash bargaining, ceteris paribus. By definition, the rigid wage regime prevents wages from responding to higher firing taxes, and thereby ameliorates negative effects on labor market outcomes.

\subsection{Labor Market Frictions and Turbulence}

Ljungqvist and Sargent (1998, 2002) have stressed the role of idiosyncratic variance or turbulence in the rise of European unemployment. In their analy- 
Figure 3: Regime Valuation for Baseline Model with Alternative Renegotiation Costs $(\rho)$ and Firing Taxes $(T)$

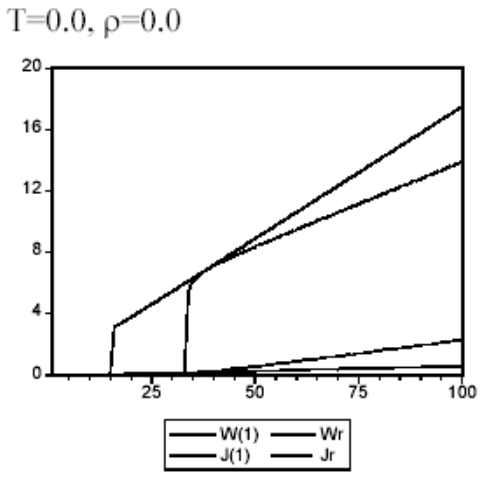

$\mathrm{T}=0.75, \rho=0.0$

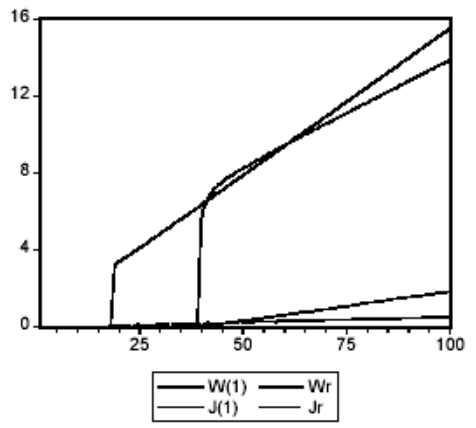

$\mathrm{T}=1.25, \rho=0.0$

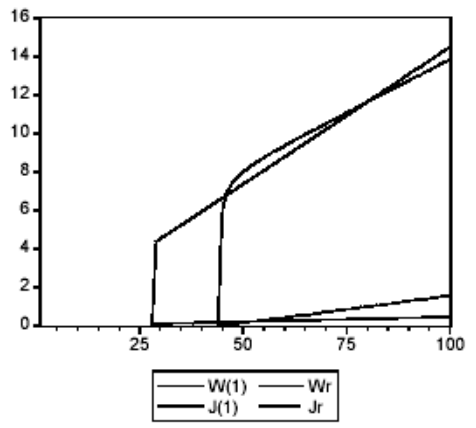

$\mathrm{T}=0.0, \rho=0.25$

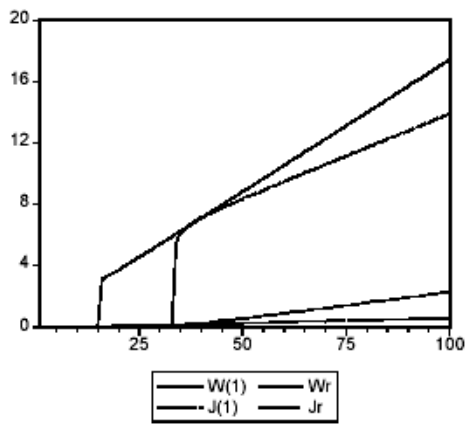

$\mathrm{T}=0.75, \rho=0.25$

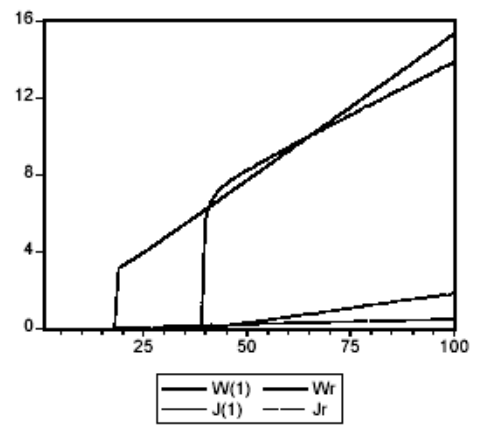

$\mathrm{T}=1.25, \rho=0.25$

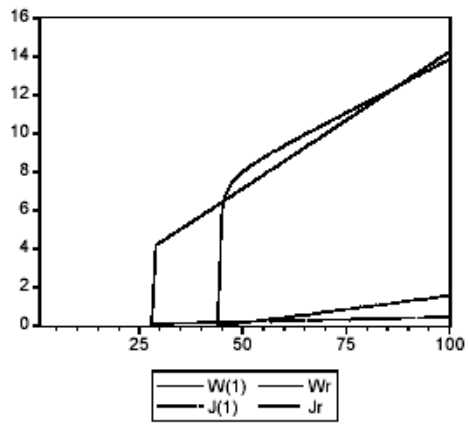

$\mathrm{T}=0.0, \rho=0.50$

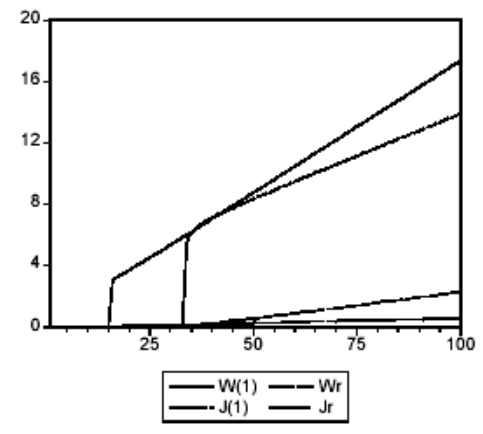

$\mathrm{T}=0.75, \rho=0.50$

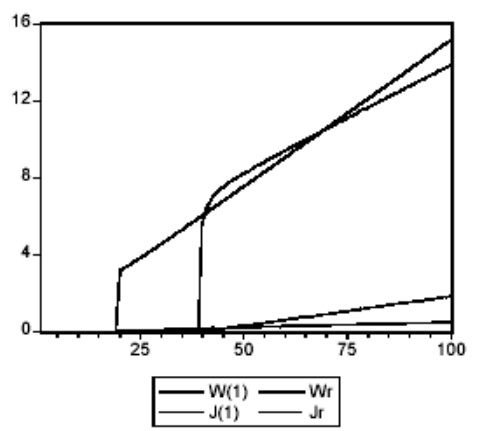

$\mathrm{T}=1.25, \rho=0.50$

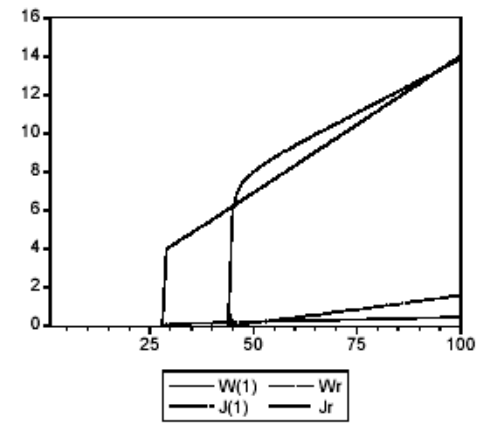


sis, increasing rates of job destruction interacting with labor market policies - unemployment benefits and/or severance regulation - have led to lower turnover and increased unemployment durations. The empirical stylized fact which has motivated this strand of the literature is an increasing fraction of earnings variance in the United States which cannot be accounted for by observable factors. Our model should have something to say about these issues, in particular: under what conditions could turbulence - the rate at which jobs are subjected to productivity changes - induce workers and firms to prefer rigid to individualized Nash-bargained wages?

To address this question, we consider the regime valuations of workers and firms for different combinations of shock incidence parameter $\lambda$ and the renegotiation costs $\rho$ while maintaining otherwise model parameter settings at benchmark values. In addition, we consider variation of $\lambda$ juxtaposed against variation in the firing $\operatorname{tax}(T)$. The results are displayed in the panels of Figures 4 and 5. Both diagrams show increasing support for a rigid wage regime in the middle of the productivity distribution when turbulence increases in the labor market, and that this support is increasing in the levels of the two frictions. Figure 4 suggests that support to rigid wages among the workers with the highest skill levels is stronger when $\lambda$ is larger. This result can only partly be attributed to savings on renegotiation costs: support for wage rigidity is increasing in $\lambda$ also under relatively low levels of $\rho$. From Figure 5, it appears that positive levels of the firing tax are necessary for increasing turbulence to translate into increasing support for wage rigidity.

\subsection{Firing Taxes and Vacancy/Setup Costs}

Finally, we turn to another important institutional feature in the MP model of equilibrium unemployment, the cost to a firm of posting and maintaining a vacancy while searching for a worker. Broadly interpreted, these costs are a stand-in for all setup costs related to a firm's entering a market and are sometimes linked to product market regulation. Product market regulation has gained prominence in recent discussions of European unemployment, as well as in the determinants of economic backwardness and development. ${ }^{13}$ According to the World Bank (Djankov, et al. (2002)) large differences can be observed across European economies in this regard: for example, it is

\footnotetext{
${ }^{13}$ See Djankov et al. (2002), Nickell (1999), Boeri et al. (1999), Blanchard and Giavazzi (2003), Haefke and Ebell (2003) and St-Paul (2004).
} 
Figure 4: Regime Valuation for Baseline Model with Alternative Renegotiation Costs $(\rho)$ and Rates of Turbulence $(\lambda)$
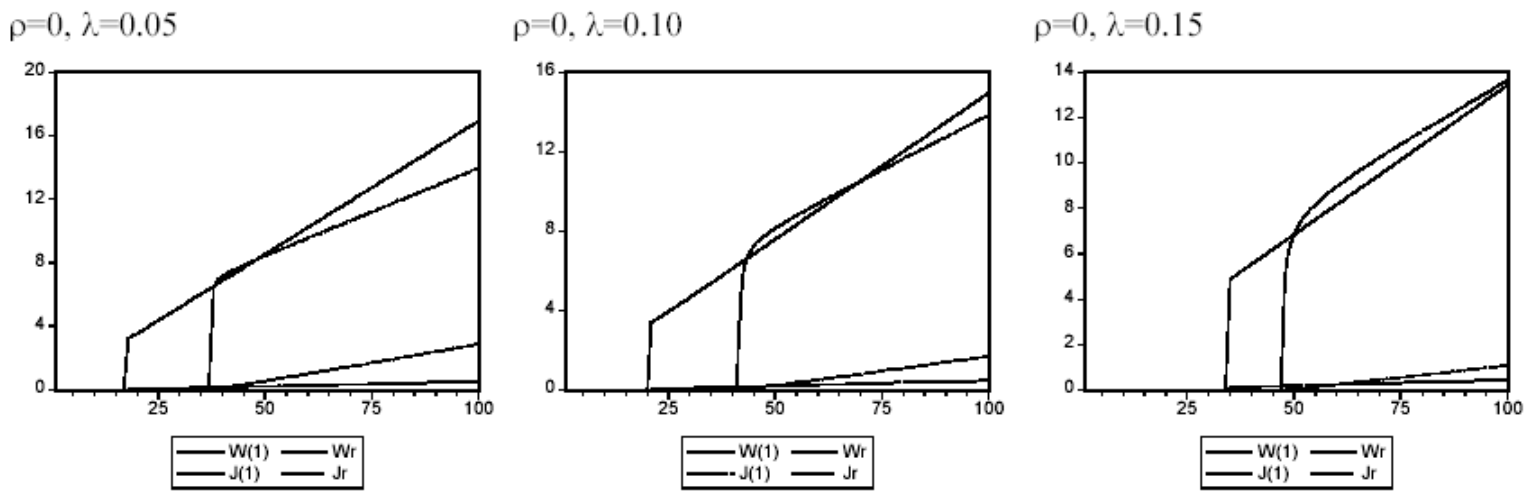

$\rho=0.25, \lambda=0.05$

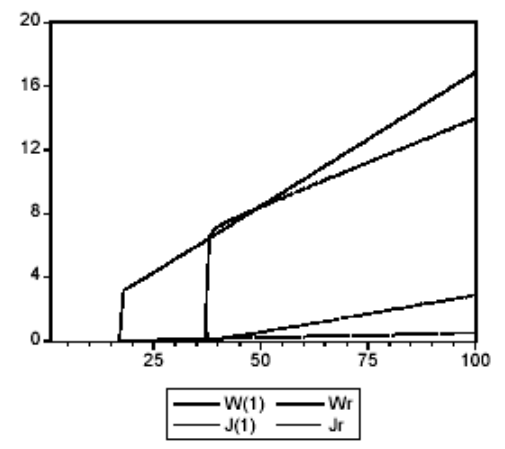

$\rho=0.50, \lambda=0.05$

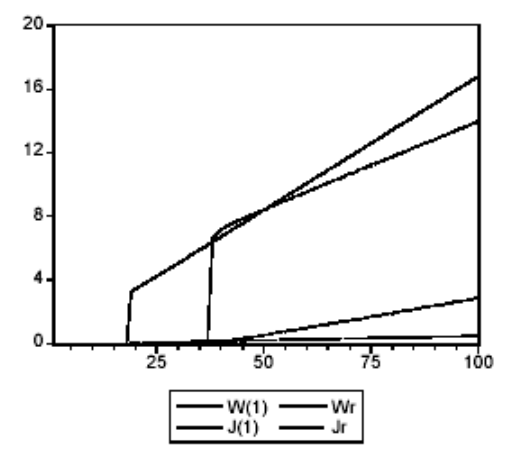

$\rho=0.25, \lambda=0.10$

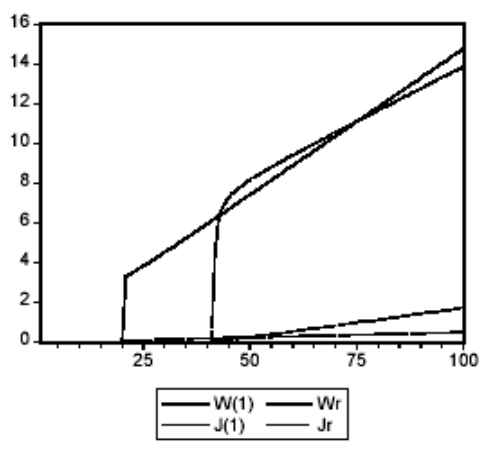

$\rho=0.50, \lambda=0.10$

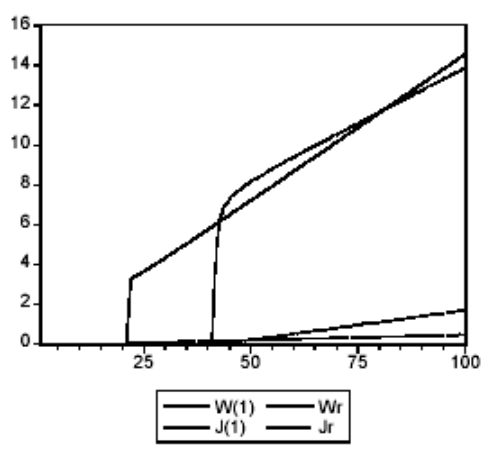

$\rho=0.25, \lambda=0.15$

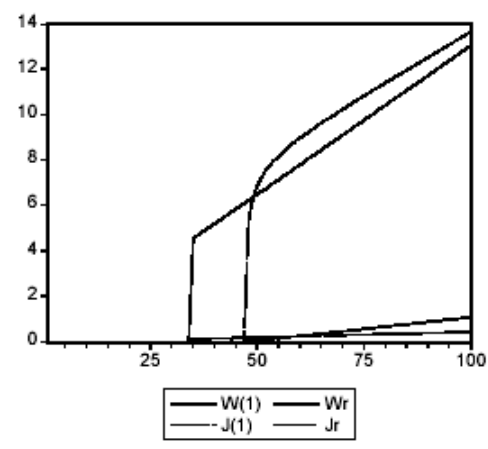

$\rho=0.50, \lambda=0.15$

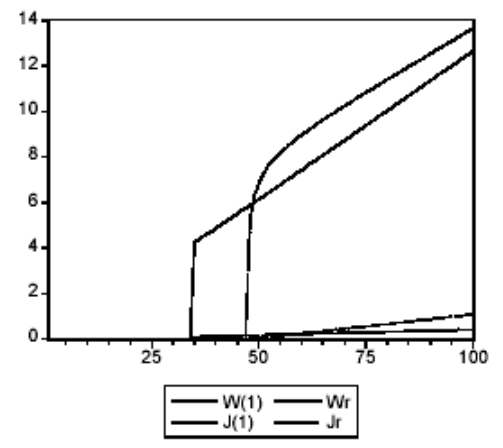


Figure 5: Regime Valuation for Baseline Model with Alternative Firing Taxes $(T)$ and Rates of Turbulence $(\lambda)$

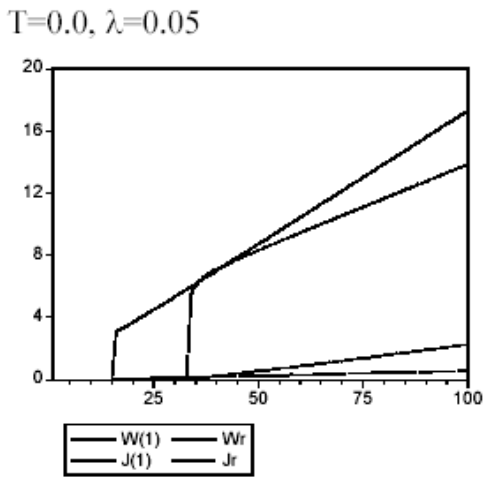

$\mathrm{T}=0.75, \lambda=0.05$

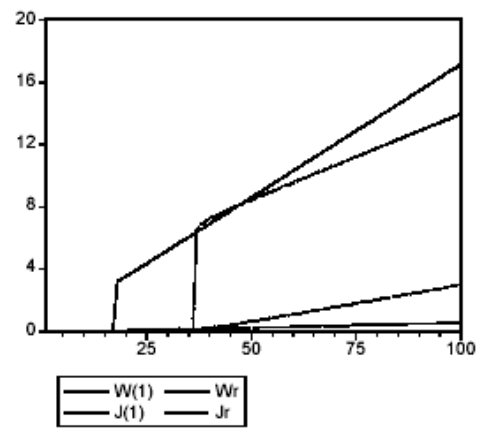

$\mathrm{T}=1.25, \lambda=0.05$

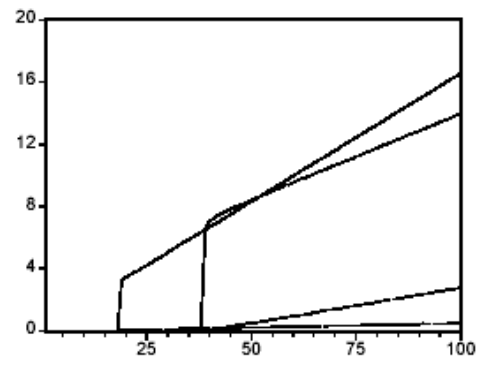

$\square_{\mathrm{J}(1)}^{W(1)}-\mathrm{Jr}_{\mathrm{Jr}}$
$\mathrm{T}=0.0, \lambda=0.10$

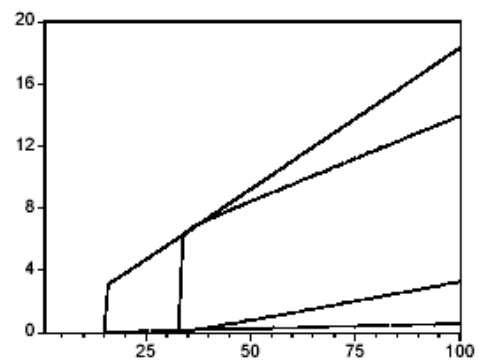

${ }_{\mathrm{J}(1)}^{\mathrm{W}(1)}-\mathrm{Jr}_{\mathrm{Jr}}^{\mathrm{Wr}}$

$\mathrm{T}=0.75, \lambda=0.10$

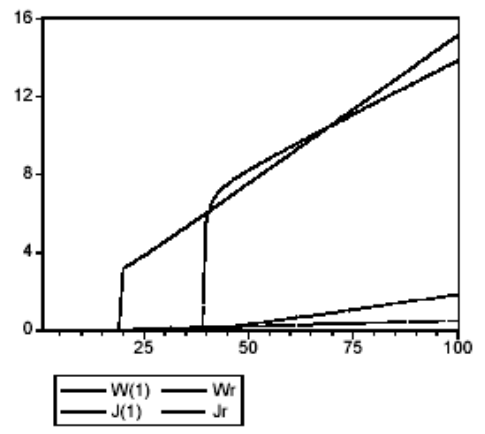

$\mathrm{T}=1.25, \lambda=0.10$

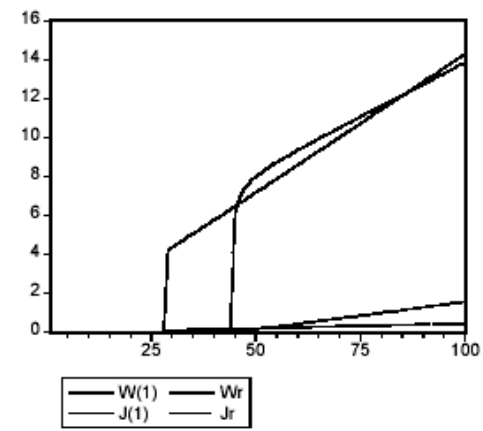

$\mathrm{T}=0.0, \lambda=0.15$

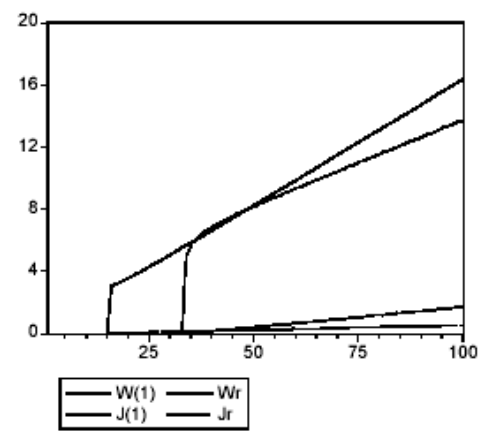

$\mathrm{T}=0.75, \lambda=0.15$

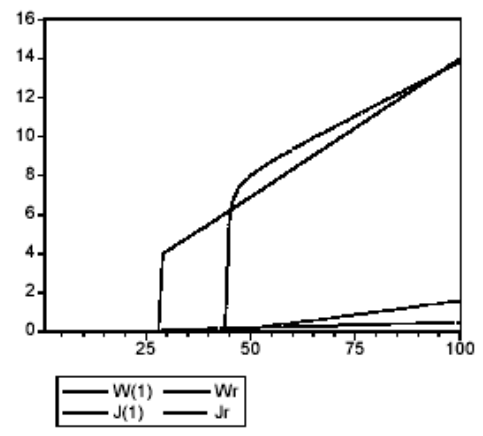

$\mathrm{T}=1.25, \lambda=0.12 *$

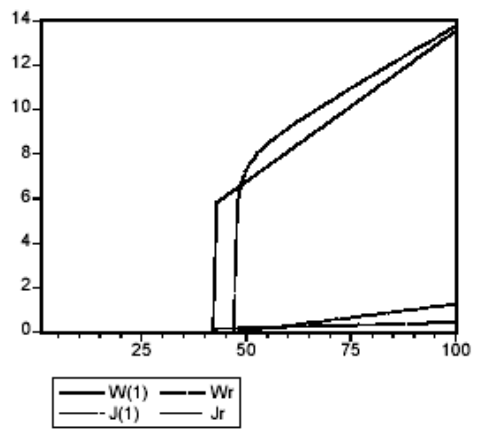


estimated that the number of days required to start a company varies in the European Union from 4 days in Denmark, 11 days in the Netherlands and 18 days in the United Kingdom, to 45, 49, and 56 days in Germany, France and Belgium respectively.

Figure 6 displays state valuations for workers in employment and filled jobs in the benchmark case, which result from variation in values of the firing tax $(T)$ and vacancy/setup costs $k$. A similar result emerges to that in the case of renegotiation costs: when $T=0$ workers never prefer rigid over individually bargained wages, regardless of the value of $k$. When $T>0$, on the other hand, skill segments exist which prefer rigid wages, and their mass is increasing with $k$, evidence of complementarity between the two parameters.

\section{Conclusions}

Equilibrium unemployment theory can shed new light on the preferences of workers and firms for different regimes of wage determination. Our main results can be summarised as follows. First, the introduction of renogotiation costs in a competitive search market makes a rigid wage regime attractive to a nontrivial segment of the working population, but only if firing frictions are already in place. Support for rigid wage regimes may be expressed as membership in a labor union, but also as political endorsement of rigid wage policies, such as minimum wage policies and the extension of contract wages to nonunionized workers. Interestingly, the lowest and the highest skilled workers will prefer the competitive search market: the former, because they are otherwise frozen out of access to a job; the latter, because they can do better in competitive search markets. This is consistent with the observation of higher union coverage rates at the middle of the earnings distribution. ${ }^{14}$

A second finding is that severance protection, in the form of a deadweight firing tax, increases the relative popularity of rigid wage policies, because it further increases utility of rigid wage workers who keep their jobs, measured relative to the competitive search equilibrium. Although severance taxation is a deadweight loss for the labor market, it can increase the appeal of rigid wage relative to Nash-bargained wages for middle-level skills. The effect arises because rigid wages prevent workers from exploiting the improvement

\footnotetext{
${ }^{14}$ See Boeri and Burda (2004) for empirical evidence on union membership and coverage rates in EU countries.
} 
Figure 6: Regime Valuation for Baseline Model with Alternative Firing TAXes $(T)$ And VACANCy/SETUP COSTS $(k)$

$\mathrm{T}=0.0, \mathrm{k}=0.10$

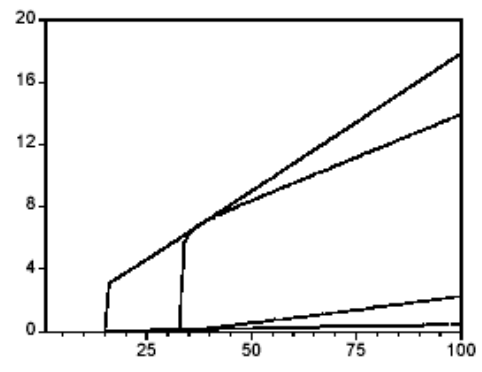

${ }_{\mathrm{J}(1)}^{W(1)-W_{\mathrm{Jr}}}$
$\mathrm{T}=0.0, \mathrm{k}=0.30$

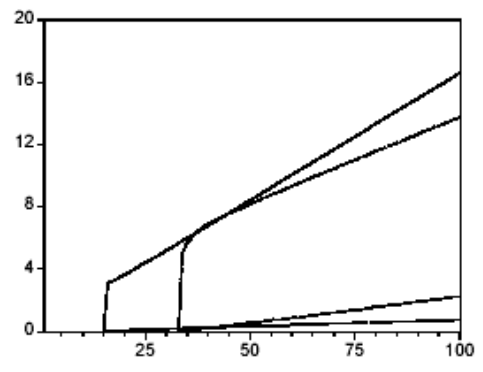

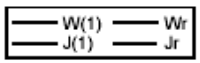

$\mathrm{T}=0.0, \mathrm{k}=0.60$

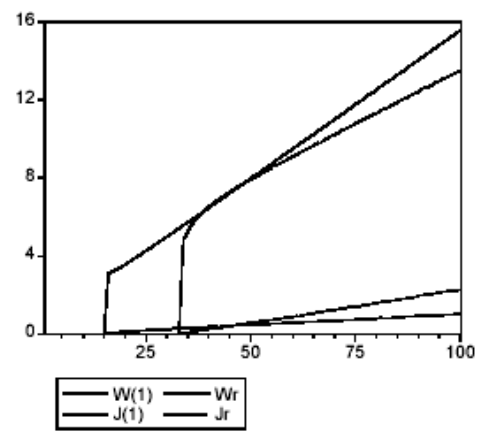

$\mathrm{T}=0.75, \mathrm{k}=0.60$

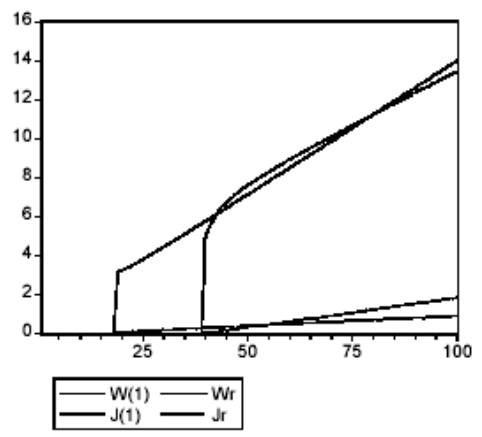

$\mathrm{T}=1.25, \mathrm{k}=0.60$

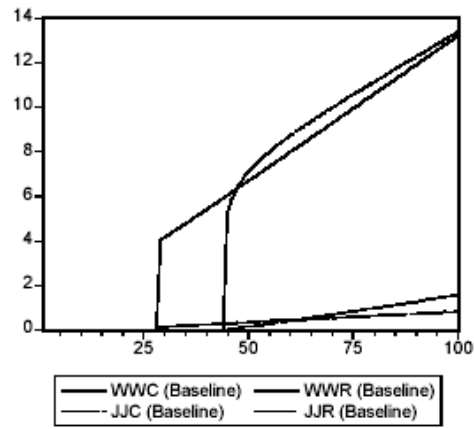


of their bargaining position which arises after an employment relationship is initiated. This mitigates the negative effect of the firing tax on job creation, while delaying job destruction. Significantly and perhaps not surprisingly, support for rigid wages by firms is significant, especially those employing higher skilled labor.

Third, our results point to strong complementarities between various types of labor market rigidities. In particular, firing taxes play a central role in our results. Not only do they increase the attractiveness of wage rigidity in the first instance, they also work in conjunction with other frictions to accentuate the attractiveness of rigid wages. When the firing tax is set equal to zero, the individually negotiated wage is preferred by most labor markets, except when the renegotiation costs are unrealistically high. In a related vein, we find that the appeal of the rigid wage regimes increases at times of greater uncertainty about the viability of job-worker matches. Workers located at the upper end of the skill distribution are more likely to endorse a rigid-wage regime when productivity shocks are more frequent, even when renegotiation costs are negligible.

It is relatively straightforward to relate our results to issues involving collective bargaining and union coverage. Although the wage rule was taken as given, it could be chosen optimally from the perpective of some agent or set of agents. For example, an economy choosing among linear wageproductivity rules might select the value of $\phi$ most preferred by the median voter of all employed workers (employed worker of median productivity); one might alternatively give some weight to the unemployed in each labor market as well as those workers in closed labor markets. Indeed, one might consider a value of $\phi$ collectively determined in an economy-wide Nash bargain between workers and firms. All these variations represent vistas for future research.

\section{References}

Bertola, G. and Rogerson, R. (1997) "Institutions and Labor Reallocation," European Economic Review, 41, 1147-71.

Boeri, T., Brugiavini, A. and Calmfors, L. (2001) (eds.) The Role of Unions in the Twenty-First Century Oxford: Oxford University Press, 2001.

Boeri, T., G. Nicoletti and S. Scarpetta (1999) "Regulation and Labor Market Performance," in G. Galli .and J. Pelkmans, eds. Regulatory Reform and Competitiveness in Europe Northampton, MA: Edward Elgar. 
Booth, A. (1995) The Economics of the Trade Unions, Cambridge: Cambridge University Press.

Blanchard, O. and Giavazzi, F. (2003) "Macroeconomic Effects of Regulation and Deregulation in Goods and Labor Markets," Quarterly Journal of Economics 118, 879-907.

Brüggemann, J. (2004) "Does Employment Protection Create Its Own Political Support? The Role of Wage Determination" mimo, MIT, March.

Boeri, T. and M. Burda (2004) "Why is there Excess Coverage?" mimeo, IGIER Bocconi University, April.

Burda, M. (1992) "A Note on Firing Costs and Severance Benefits in Equilibrium Unemployment," Scandinavian Journal of Economics 94:3, 479489.

Coe, D. and D. Snower (1997): "Policy Complementarities: The Case for Fundamental Labour Market Reform," IMF Staff Papers 44:1-35.

Djankov, S. R. LaPorta, F. Lopez-de-Silanes, and A. Shleifer (2002) "The Regulation of Entry" Quarterly Journal of Economics 117: 1-37.

Ebell, M. and C. Haefke (2003) "Product Market Deregulation and Labor Market Outcomes" mimeo, December.

Ebbinghaus, B. and J.Visser (2000). Trade Unions in Western Europe since 1945. London: McMillan.

Garibaldi, P. and G. Violante (2004) "The Employment Effects of Severance Payments with Wage Rigidities" mimeo, January.

Hosios, A.J., (1990) "On the Efficiency of Matching and Related Models of Search and Unemployment," Review of Economic Studies, 57: 279-298.

Lazear, E. (1990) "Job Security Provisions and Unemployment", Quarterly Journal of Economics 105: 699-726.

Ljungqvist, L. (2002) "How Do Layoff Costs Affect Employment?", Economic Journal, vol. 112, 829-853.

Ljungqvist, L. and T. Sargent (1998) "The European Unemployment Dilemma" Journal of Political Economy 106: 514-550.

Ljungqvist, L. and T. Sargent (2002) "The European Employment Experience," CEPR Discussion paper 3543 September.

Millard, S. and D. Mortensen (1997) "The Unemployment and Welfare Effects of Labour Market Policy: a Comparison of the USA and the UK," in: Snower and de la Dehesa, eds., Unemployment Policy: Government Options for the Labour Market Cambridge: Cambridge University Press.

Mortensen, D. and C. Pissarides (1994) "Job Creation and Job Destruction in the Theory of Equilibrium Unemployment", Review of Economic 
Studies 61:397-415.

Mortensen, D. and Pissarides, C. (1999a) "Unemployment Responses to 'Skill-biased' Technology Shocks: The Role of Labour Market Policy," The Economic Journal 109: 242-265.

Mortensen, D. and Pissarides, C. (1999b) New Developments in Models of Search in the Labour Market, in Ashenfelter and Card (eds.) Handbook of Labour Economics, North Holland, Amsterdam pp. 2589-2601.

Nickell, S. (1999) "Product Markets and Labor Markets" Labour Economcs 6: $1-20$.

Petrongolo, B. and Pissarides, C. (2000) "Looking into the Black Box: A Survey of the Matching Function," Journal of Economic Literature. 39: 390-431.

Pissarides, C. (2000) Equilibrium Unemployment Theory, Cambridge USA: MIT Press.

St.-Paul, G. (2000) The Political Economy of Labour Market Institutions Oxford: Oxford University Press.

St.-Paul, G. (2004) "Did European Labor Markets Become More Competitive in the 1990s? Evidence from Estimated Worker Rents," IZA Discussion Paper No.1067.

Yashiv, E. (2000) "The Determinants of Equilibrium Unemployment" American Economic Review 90, 1297-1322. 


\section{Appendix}

\subsection{Derivation of job creation conditions in the rigid wage regime}

Use the equilibrium valuation equation (8) to value a job under the rigid wage regime at $x=R^{r}$, imposing $V^{r}=0$ and the fact that at the destruction margin by definition $J^{r}\left(R^{r}\right)+s T=0$, to solve for $\lambda \int_{R^{r}}^{1} J^{r}(z) d F(z)$ :

$$
\lambda \int_{R^{r}}^{1} J^{r}(z) d F(z)=w^{r}-s R^{r}-\left[r+\lambda\left(1-F\left(R^{r}\right)\right)\right] s T
$$

Substitute this into (8) with $V^{r}=0$ and obtain

$$
(r+\lambda) J^{r}(x)=s\left(x-R^{r}\right)-(r+\lambda) s T .
$$

Now set $x=1$ and use the zero profit condition in the rigid wage regime (10) to obtain the JC-condition:

$$
\begin{aligned}
(r+\lambda) J^{r}(1) & =s\left(1-R^{r}-(r+\lambda) T\right)=(r+\lambda)\left[\frac{s k}{q\left(\theta^{r}\right)}\right] \\
& \Rightarrow \frac{\left(1-R^{r}\right)}{(r+\lambda)}-T=\frac{k}{q\left(\theta^{r}\right)}
\end{aligned}
$$

The derivation for the flexible wage case (e.g. Pissarides 2000) simply replaces $w^{r}$ with the competitive analog (13), and similar manipulations lead to the JC-condition for the individually negotiated wage case:

$$
(1-\beta)\left(\frac{1-R}{r+\lambda}-T\right)=\frac{k}{q(\theta)} .
$$

\subsection{Derivation of job destruction condition in the rigid wage regime}

Rewrite the job valuation equation (8) and impose $V^{r}=0$ to obtain

$$
(r+\lambda) J^{r}(x)=s x-w^{r}+\lambda \int_{R^{r}}^{1} J^{r}(z) d F(z)-\lambda F\left(R^{r}\right) s T .
$$


Substitute $J^{r}(z)=\frac{s\left(z-R^{r}\right)}{(r+\lambda)}-s T$ in the integral on the right hand side:

$$
\begin{aligned}
(r+\lambda) J^{r}(x)= & s x-w^{r}+\lambda \int_{R^{r}}^{1} \frac{s\left(z-R^{r}\right)}{r+\lambda} d F(z) \\
& -\lambda\left[1-F\left(R^{r}\right)\right] s T-\lambda F\left(R^{r}\right) s T \\
= & s x-w^{r}+\frac{\lambda s}{r+\lambda} \int_{R^{r}}^{1}\left(z-R^{r}\right) d F(z)-\lambda s T .
\end{aligned}
$$

Imposing $x=R^{r}$ and $J^{r}\left(R^{r}\right)=-s T$ yields the condition for job destruction

$$
w^{r}=s R^{r}+\frac{\lambda s}{(r+\lambda)} \int_{R^{r}}^{1}\left(z-R^{r}\right) d F(z)+r s T
$$

Now substitute $w^{r}=\bar{w}+\phi s$ and rearrange:

$$
s R^{r}+\frac{\lambda s}{r+\lambda} \int_{R^{r}}^{1}\left(z-R^{r}\right) d F(z)=\bar{w}+\phi s-r s T
$$

The flexible wage case is solved analogously to the rigid case (See Mortensen and Pissarides (1999a,b)

$$
s R+\frac{s \lambda}{r+\lambda} \int_{R}^{1}(z-R) d F(z)=b+\frac{\beta s k \theta}{1-\beta}+\lambda[1-F(R)] \rho-r s T .
$$

\subsection{Comparative statics in the rigid wage regime}

The two equations for the job destruction and creation conditions under rigid wages, rewritten slightly:

$$
\begin{gathered}
R^{r}+\frac{\lambda}{r+\lambda} \int_{R^{r}}^{1}\left(z-R^{r}\right) d F(z)=\frac{\bar{w}}{s}+\phi-r T \\
\frac{k}{q\left(\theta^{r}\right)}=\frac{\left(1-R^{r}\right)}{(r+\lambda)}-T
\end{gathered}
$$

Differentiation and rearrangement leads to the form $\mathbf{A}^{r}\left[\begin{array}{l}d R^{r} \\ d \theta^{r}\end{array}\right]=\mathbf{b}^{r}$, with $\mathbf{A}=\left[\begin{array}{ll}1-\frac{\lambda}{r+\lambda}\left(1-R^{r}\right) & 0 \\ \frac{1}{r+\lambda} & -\frac{k q^{\prime}}{q^{2}}\end{array}\right]$, and $\mathbf{b}=\left[\begin{array}{c}\frac{d \bar{w}}{s}-\frac{\bar{w}}{s^{2}} d s+d \phi-r d T-T d r \\ -\frac{1-R^{r}}{(r+\lambda)^{2}}(d r+d \lambda)-d T-\frac{d k}{q}\end{array}\right]$ 
Inspection reveals that the determinant of $\mathbf{A}$ is now given by $\Delta^{r} \equiv$ $\left[1-\frac{\lambda}{r+\lambda}\left(1-R^{r}\right)\right]\left[-\frac{k q^{\prime}}{q^{2}}\right]$ which is also unambiguously positive. The comparative statics results are

$$
\begin{aligned}
& \frac{\partial R^{r}}{\partial s}=\frac{\frac{\bar{w}}{s^{3}} \frac{k q^{\prime}}{q^{2}}}{\Delta^{r}}<0 ; \frac{\partial \theta^{r}}{\partial s}=\frac{\frac{\bar{w}}{s^{2}(r+\lambda)}}{\Delta^{r}}>0 \\
& \frac{\partial R^{r}}{\partial \bar{w}}=\frac{-\frac{k q^{\prime}}{s q^{2}}}{\Delta^{r}}>0 ; \frac{\partial \theta^{r}}{\partial \bar{w}}=\frac{-\frac{1}{s(r+\lambda)}}{\Delta^{r}}<0 \\
& \frac{\partial R^{r}}{\partial \phi}=\frac{-\frac{k q^{\prime}}{q^{2}}}{\Delta^{r}}>0 ; \frac{\partial \theta^{r}}{\partial \phi}=\frac{-\frac{1}{(r+\lambda)}}{\Delta^{r}}<0 \\
& \frac{\partial R^{r}}{\partial b}=\frac{\partial R^{r}}{\partial \beta}=\frac{\partial R^{r}}{\partial \rho}=0 ; \frac{\partial \theta^{r}}{\partial b}=\frac{\partial \theta^{r}}{\partial \beta}=\frac{\partial \theta^{r}}{\partial \rho}=0 \\
& \frac{\partial R^{r}}{\partial T}=\frac{r \frac{k q^{\prime}}{q^{2}}}{\Delta^{r}}<0 ; \frac{\partial \theta^{r}}{\partial T}=\frac{-\frac{\lambda}{r+\lambda} R^{r}}{\Delta^{r}}<0 \\
& \frac{\partial R^{r}}{\partial r}=\frac{-T \frac{k q^{\prime}}{q^{2}}}{\Delta^{r}}>0 ; \frac{\partial \theta^{r}}{\partial r}=\frac{\frac{T}{(r+\lambda)}}{\Delta^{r}}>0
\end{aligned}
$$

\subsection{Derivation of the Equilibrium Labor Market State Valuations}

In this section we derive expressions for the equilibrium capital asset values of the state of employment at full initial productivity $\left(W(1)\right.$ or $\left.W^{r}\right)$, and the value of a newly-filled vacancy $\left(J(1)\right.$ or $\left.J^{r}(1)\right)$.

\subsubsection{Flexible Wage Regime}

Rearrange the first order condition or sharing rule (11) using (15), and (12) to get

$$
W(1)=\frac{b}{r}+\frac{\beta s\left(1-R^{*}\right)}{(r+\lambda)}+\frac{\beta s k \theta^{*}}{r(1-\beta)}
$$

SO

$$
\frac{\partial W(1)}{\partial s}=\frac{\beta\left(1-R^{*}\right)}{(r+\lambda)}+\frac{\beta k \theta^{*}}{r(1-\beta)}-\frac{\beta s}{(r+\lambda)} \frac{\partial R^{*}}{\partial s}+\frac{\beta s k}{r(1-\beta)} \frac{\partial \theta^{*}}{\partial s}
$$




$$
=\frac{\beta}{(r+\lambda) r}\left[r\left(1-R^{*}\right)+\frac{(r+\lambda) \beta k \theta^{*}}{(1-\beta)}-r s \frac{\partial R^{*}}{\partial s}+\frac{k(r+\lambda)}{(1-\beta)} \frac{\partial \theta^{*}}{\partial s}\right]>0 .
$$

so in $(s, W)$ space, the valuation of the competitive employment state is strictly increasing in skill $s$. Intuitively, $s$ has three effects on the valuation of a job. First it increases the flow payoff in all cases that the job survives. Second it lowers the threshold value of productivity, holding all else constant, and thereby increases the expected duration of the job. Finally, it raises equilibrium job tightness in the local labor market, raising the probability of finding a job in that labor market, given that one is unemployed.The sign of the second derivative involves the curvature of response of $R^{*}$ and $\theta^{*}$ respectively to $s$ :

$$
\frac{\partial W^{2}(1)}{\partial s^{2}}=-\frac{\beta}{(r+\lambda)}\left[\frac{\partial R^{*}}{\partial s}+s \frac{\partial^{2} R^{*}}{\partial s^{2}}\right]+\frac{\beta k}{r(1-\beta)}\left[\frac{\partial \theta^{*}}{\partial s}+s \frac{\partial^{2} \theta^{*}}{\partial s^{2}}\right]
$$

and is ambiguous. One sufficient condition for convexity of the value of competitive segment employment is that $R^{*}$ and $\theta^{*}$ are not too responsive to $s: \frac{s \frac{\partial^{2} R^{*}}{\partial s^{2}}}{\frac{\partial R^{*}}{\partial s}}<1$ and $\frac{s \frac{\partial^{2} \theta^{*}}{\partial s^{2}}}{\frac{\partial \theta^{*}}{\partial s}}>-1$.

For the valuation of firms, we have

$$
J(1)=\frac{s k}{q(\theta)}
$$

and differentiate, obtaining:

$$
\frac{\partial J(1)}{\partial s}=\frac{k}{q(\theta)}-\frac{s k q^{\prime}}{q^{2}} \frac{\partial \theta}{\partial s}>0
$$

so that an increase in skills unambiguously increases the value of the firm (filled job). For the same reasons as above, the sign of the second derivative of $J(1)$ with respect to $s$ cannot be determined unambiguously.

The derivatives of the equilibrium valuations of employment and filled jobs can be obtained in a straightforward way and their signs are summarized in the Table A1.

TABLE A1
\begin{tabular}{|l|l|l|l|l|l|}
\hline Effect of $\ldots$ & $b$ & $\rho$ & $\lambda$ & $\beta$ & $k$ \\
\hline$\ldots$ on & & & & & \\
\hline$W(1)$ & $?$ & - & - & + & - \\
\hline$J(1)$ & - & - & - & - & $?$ \\
\hline
\end{tabular}


The valuation of unemployment $U$ is straightforward:

$$
\begin{aligned}
r U & =b+\theta q(\theta)[W(1)-U] \\
{[r+\theta q(\theta)] U } & =b+\theta q(\theta) W(1) \\
U & =\frac{b+\theta q(\theta) W(1)}{r+\theta q(\theta)} \\
W(1)-U & =\frac{r W(1)-b}{r+\theta q(\theta)}
\end{aligned}
$$

but $r W(1)=b+\frac{r \beta s\left(1-R^{*}\right)}{r+\lambda}+\frac{\beta s k \theta^{*}}{1-\beta}$ so

$$
\begin{aligned}
W(1)-U & =\frac{\frac{r \beta s\left(1-R^{*}\right)}{(r+\lambda)}+\frac{\beta s k \theta^{*}}{(1-\beta)}}{r+\theta q(\theta)} \\
W(1)-U+J(1) & =\frac{\frac{r \beta s\left(1-R^{*}\right)}{(r+\lambda)}+\frac{\beta s k \theta^{*}}{(1-\beta)}}{r+\theta q(\theta)}+\frac{s k}{q(\theta)} \\
S(1) & =\left[\frac{\frac{r \beta\left(1-R^{*}\right)}{(r+\lambda)}+\frac{\beta k \theta^{*}}{(1-\beta)}}{r+\theta q(\theta)}+\frac{k}{q(\theta)}\right] s
\end{aligned}
$$

\subsubsection{Rigid Wage Regime}

Combining (7) and (5) and solving we obtain:

$$
W^{r}=\frac{b}{r}+\frac{1}{1+\frac{\lambda F\left(R^{r}\right)}{r+\theta^{r} q\left(\theta^{r}\right)}}\left[\frac{(\bar{w}+\phi s)-b}{r}\right] .
$$

Note that if $\bar{w}=b$,

$$
W^{r}=\frac{1}{r}\left[b+\frac{1}{1+\frac{\lambda F\left(R^{r}\right)}{r+\theta^{r} q\left(\theta^{r}\right)}} \phi s\right] .
$$

As in the individualized-wage segment, it is possible to show that $W^{r}$ is unambiguously increasing in skill $s$. Intuitively, raising $s$ raises the value of employment because it increases pay directly, as well as equilibrium job tightness in the local labor market, raising the probability of finding a job. It also increases the duration of a job. As long as $\phi$ is strictly positive, 
higher skills will be associated with a higher flow payoff in the continuation region. As in the competitive case, the sign of the second derivative of $W^{r}$ is ambiguous.

For the valuation of firms we have

$$
J^{r}(1)=\frac{s k}{q\left(\theta^{r}\right)}
$$

Differentiate to obtain

$$
\frac{\partial J^{r}(1)}{\partial s}=\frac{k}{q\left(\theta^{r}\right)}-\frac{s k q^{\prime}}{q^{2}} \frac{\partial \theta^{r}}{\partial s}>0
$$

unambiguously. As in the individualized wage regime, the second derivative of $J^{r}(1)$ is ambiguous.

Table A2 summarizes the effects of other changes on $W^{r}(1)$ and $J^{r}(1)$ conditional on the match surviving:

TABLE A2
\begin{tabular}{|l|c|c|c|c|}
\hline Effect of $\ldots$ & $\bar{w}$ & $\phi$ & $\lambda$ & $T$ \\
\hline$\ldots$ on & & & & \\
\hline$W^{r}(1)$ & + & + & - & - \\
\hline$J^{r}(1)$ & - & - & - & + \\
\hline
\end{tabular}

As for the match surplus, use as before the fact that $W^{r}-U=\frac{r W^{r}-b}{r+\theta^{r} q\left(\theta^{r}\right)}$ so that we have

$$
\begin{aligned}
W^{r}-U^{r} & =\frac{\bar{w}+\phi s-b}{r+\theta^{r} q\left(\theta^{r}\right)+\lambda F\left(R^{r}\right)} \\
S^{r}(1) & =W^{r}-U^{r}+J^{r}(1)=\frac{\bar{w}+\phi s-b}{r+\theta^{r} q\left(\theta^{r}\right)+\lambda F\left(R^{r}\right)}+\frac{s k}{q\left(\theta^{r}\right)} .
\end{aligned}
$$

If $\bar{w}=b$, we have:

$$
S^{r}(1)=\left[\frac{\phi}{r+\theta^{r} q\left(\theta^{r}\right)+\lambda F\left(R^{r}\right)}+\frac{k}{q\left(\theta^{r}\right)}\right] s .
$$

